\title{
A COMPLEX ADAPTIVE SYSTEM IN WHICH ENVIRONMENTAL STRESS AFFECTS GENE EXPRESSION DURING DEVELOPMENT
}

\author{
K.S.B. KOH $^{1}$, V.K.L. TOH ${ }^{1}$, M. BROOK O'DONNELL ${ }^{2}$, S. RANJTKAR ${ }^{1}$ \& A. H. BROOK ${ }^{1,3}$ \\ ${ }^{1}$ School of Dentistry, University of Adelaide, Australia. \\ ${ }^{2}$ Annenberg School of Communication, University of Pennsylvania. \\ ${ }^{3}$ Institute of Dentistry, Queen Mary University of London, England.
}

\begin{abstract}
Dental development is a complex adaptive system influenced by genetic-epigenetic-environmental factors. The mature dentition is a paradigm for general development and is an accessible, permanent record of interactions affecting development from 6 weeks in-utero to 20 years of age. Published research on the dentition of a large group of Romano-Britons has indicated that three major environmental insults acting throughout the developmental period are associated with high frequencies of dental variations. Based on those studies and the literature, the aetiological network incorporates the effects of excessive lead ingestion, poor nutrition and infections on the endocrine and immune systems, epigenome and gene expression. The environmental insults act independently and synergistically on both the endocrine and immune systems, which in turn have reciprocal interactions with each other, as well as on the epigenome. Thus, a complex subnetwork influences the epigenome and modifies one or more of three mechanisms by which it controls gene expression, that is, DNA methylation, post-translational histone modification and microRNA expression. The environmental-epigeneticgenetic interactions behave as a complex adaptive system that can be illustrated in a network diagram. The epigenetic modifications can have long-term health effects in the individual and some may also be heritable.

Keywords: complex adaptive system, dental development, environmental stress, epigenetics, gene expression, general development, Romano-Britons.
\end{abstract}

\section{INTRODUCTION}

Environmental stress is associated with significant health problems. In this paper, we explore its impact on the development of dentition which is a valuable paradigm for general development. The aim is to advance previous work by exploring further the actions of the environmental factors identified as having major impact in a group of Romano-Britons, and to model a complex network involving the interactions between environmental factors, body systems, epigenetic mechanisms and gene expression.

\subsection{Complex adaptive system}

Dental development is a complex adaptive system (CAS), and is characterised by dynamic behaviours that arise from non-linear spatial-temporal interactions among multiple component systems at different levels of organisation [1]. The ecosystem, social networks and financial systems are other examples of complex systems.

The exploration of dental development as a complex adaptive system began with Brook \& BrookO'Donnell [2]. Then, Brook et al. [3] demonstrated that the CAS characteristics of self-organisation, 
bottom-up emergence, multitasking, self-adaptation, variation, tipping points, critical phases and robustness are present in the development of dental tissues to form an integrated functional system. The interactions among multiple agents at lower molecular and cellular levels, which result in the emergence of the dentition at a higher level, are initiated by genetic, epigenetic and environmental factors. The dentition is able to adapt and evolve in changing environments during its development and as a mature system.

\subsection{Dental development as a paradigm for general development}

The formation of teeth begins with a sequential and reciprocal series of inductive signals transmitted between the epithelium and mesenchyme-derived neural crest cells [4]. Then, the dental epithelium thickens to form the dental lamina, which subsequently develops a specific number of higher-level organs, called the soft tissue tooth germs [3]. The tooth germs continue to develop morphologically into incisors, canines, premolars and molars at specific locations within the dental arches. Then, specialised cells called ameloblasts and odontoblasts differentiate to control the secretion of enamel and dentine matrices respectively. The mineralised mature teeth erupt and form a dynamic system that continues to adapt during function [5,6]. Dental development is a valuable paradigm for general development because teeth are accessible, permanent records of development that extends from 6 weeks in-utero to 20 years of age. Dental development is therefore a good model for the study of normal and variations in general development and disease.

\subsection{Genetic-epigenetic-environmental interactions}

Dental development is initiated by genetic, epigenetic and environmental interactions. Recent research in epigenetics has changed the way we think about normal development, disease states and expression of the genome. Environmental factors act on the genome by affecting epigenetic mechanisms, such as DNA methylation, histone modification and regulation of microRNAs. Epigenetic modifications influence gene expression and can result in an altered phenotype while the genomic structure remains unchanged. Interestingly, some epigenetic changes are potentially reversible, but others persist throughout life. Children born during the period of the Dutch hunger winter from 1944 to 1945 had increased rates of adult-onset diseases such as coronary heart disease and obesity when there was maternal exposure to famine during pregnancy [7]. Some epigenetic modifications have also been shown to be heritable or transgenerational. In another Dutch hunger winter study, results showed that first generation famine exposure in-utero was associated with increased second generation adiposity and poor health in later life [8]. The epigenome changes over the human lifespan. However, it is most vulnerable to environmental factors during embryogenesis when the DNA synthesis rate is high, and the elaborate DNA methylation patterning required for normal tissue development is established [9]. In-utero and early-life events can significantly modulate the epigenome and lead to altered phenotypes and disease susceptibility throughout the life course [10].

\subsection{Environmental stress in early life and dental variation: Romano-British population}

The numerous studies on the substantial skeletal material of the Romano-Britons from Poundbury, Dorset in the 200-400 A.D. provide much evidence concerning lifestyle and medical conditions [11]. Major environmental insults known to affect development in the Poundbury population were high levels of lead ingestion, poor general nutrition with identified vitamin and mineral deficiencies 
and recurrent infections [5]. The teeth and bones were found to have high lead content $[12,13]$. Possible sources of lead were lead kitchenware, and utilisation of lead for preparation of drinks in some Roman recipes [11]. Besides that, an agricultural lifestyle with cereal as the predominant element in the diet contributed to their poor nutrition [11]. High incidence of rickets and scurvy were likely to have occurred following deficiency of micronutrients, such as Vitamin $\mathrm{C}$ and D, in addition to poor maternal health during gestation [14]. Furthermore, gastrointestinal infections aggravated their nutritional status and health [15]. The findings from Brook et al. [5] were that both RomanoBritons and Modern Britons had the same general dental characteristics and types of variation. However, there were substantial differences in the dimensions of teeth and prevalence of variation between the two groups. It was suggested that the long-term environmental insults during dental development influenced this complex adaptive system to produce the greater number of phenotypic variations seen in the dentition of the Romano-Britons [5].

\section{AIMS}

The aim of this paper is to develop an aetiological network model based on findings of environmental stress from the Romano-British and Poundbury Camp studies. Following that, we will consider the multiple independent, summative, synergistic and reciprocative interactions of excessive lead ingestion, poor nutrition, and recurrent infections on the immune and endocrine systems and the epigenome.

\section{MATERIALS AND METHODS}

This paper works further to Brook et al. [5], which summarised the findings for four outcomes of dental development: tooth number; crown size and shape; root size and shape; and enamel structure scored using standardised measurements [16-18].

Here, a thorough literature search of all the interrelated effects of excessive lead ingestion, recurrent infections and poor nutrition on the immune and endocrine systems, as well as on the epigenome is reported.

\section{RESULTS AND DISCUSSION}

Our findings [5] show that in comparison with Modern Britons of European ancestry, the RomanoBritons exhibited the same types of dental development variations and sexual dimorphism but a much higher prevalence of hypodontia, smaller crown and root size, and enamel defects. These results provide evidence for environmental stress affecting phenotypic outcomes arising throughout the morphological, differentiation and calcification stages of tooth development. Different genes act during different developmental stages, so that the finding of substantial numbers and degrees of phenotypic variations in each stage is a strong indication that the aetiology of the higher prevalence of these variations is environmental rather than genetic mutations. Set out in Fig. 1 is our proposal, developed from evidence in the literature reviewed below for the complex adaptive system emerging from the interactions of these environmental agents.

\subsection{Lead}

No level of lead exposure is considered safe and its cumulative effects are harmful to body systems. Lead kitchenware and Roman recipes, which included lead for preparation of drinks, were major sources in the Romano-Briton population [11]. After ingestion, lead is stored in teeth and bones, and later bone remodelling becomes an endogenous source of lead exposure [19]. Endogenous and 


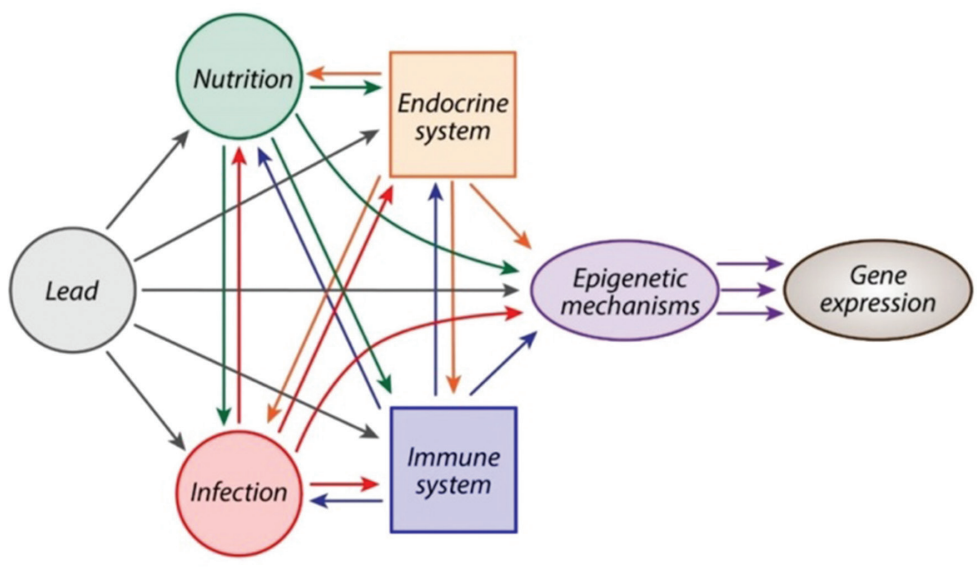

Figure 1: Environmental-epigenetic-genetic interactions. A complex adaptive system with multiple, often reciprocal interactions by which the environmental factors interact with body systems and epigenetic mechanisms to alter gene expression.

exogenous variables influencing bodily effects of lead include stress, dietary deficiencies and concomitant exposure to other chemical, biological and radiological hazards. These potentially modify, or even potentiate the toxic effects of lead [19]. In addition, lead can also cross the placenta, and the blood-brain barrier. Moreover, in-utero and lactational exposures further increase the risk of lead toxicity during the gestational and neonatal period [19].

\subsection{Effect of lead on nutrition}

Long-term effects of excessive lead ingestion include digestive disturbances, colic and diarrhoea [11]. When prolonged, these result in poor absorption of nutrients and digestive malnutrition. Besides that, environmental chemical exposure and nutrient deprivation can occur simultaneously and synergistically. For example, food chains are often contaminated by chemical agents found in soil and water. Lee et al. [20] hypothesise a unifying mechanism that attempts to link epigenetic alterations in relation to DNA hypomethylation due to chemical agents and nutrient deficiency. Both chemical exposure and nutrient deficiency may impair the synthesis of S-adenosylmethionine (SAM) via a common pathway, which results in DNA hypomethylation and modulation of the epigenome [20].

4.2.1 Effect of lead on the immune system, thus increasing the body's susceptibility to infection Lead impairs immune function and alters host resistance. Lead exposure can result in impaired immune function of T-lymphocytes and erythrocytes, and a delayed immune response [21,22]. There was a decrease in the percentage of CD4+ and significant increase in CD8+ cells in children exposed to high lead levels [23]. Lead exposure in adults produces an impaired host resistance to bacterial and viral infections $[24,25]$. In addition, lead exposure produces a shift in the functional capacity of 
the immune system, which may lead to an increased risk of atopic and autoimmune diseases, while also impairing host defenses against infections and cancer [26].

\subsubsection{Effect of lead on the endocrine system and epigenome}

Lead has been found to be an endocrine disruptor in the Drosophila fruit fly [27]. The ability of lead to act directly on the epigenome is probably one of the most important, having consequences long after this environmental stressor has been removed. Perinatal lead exposure in mice during development and lactation leads to persistent life-course changes in energy expenditure, food intake, body weight, total body fat, glucose tolerance and insulin response [28].

\subsection{Poor nutrition}

\subsubsection{Effect of poor nutrition on lead toxicity}

Dietary deficiencies modify the toxicodynamics of lead: diets deficient in iron, zinc and calcium have been shown to increase the gastrointestinal absorption of lead [19]. Furthermore, maternal dietary protein levels modify the developmental immunotoxicity of lead in rat offsprings [29]. Individuals living in developing countries are more likely to have nutritional deficiencies that increase lead absorption [30]. Children who are engaged in child labour tend to belong to the same population that is at risk of nutritional deficiencies. This enhances the adverse health effects of lead on top of increasing its absorption into the body [31].

\subsubsection{Effect of poor nutrition on the immune system}

The immune system may be compromised by nutritional deficiencies during prenatal and early postnatal life. In rural Gambia, infection-related mortality was much higher for adults born in the annual climatically determined, nutrition-deficient 'hungry' season, which suggests immune function, may be compromised by this early-life event [32]. Furthermore, thymus development during infancy is critically sensitive to environmental exposures, with smaller thymuses observed in those born in the hungry season. The compromised thymus and hence T-lymphocyte development result in defective adaptive immunity later in life.

In contrast, the combined effects of some hormones may positively affect on the immune system. Davis [33] found that nutritional deprivation, physical and emotional stress and environmental temperature are mediated by hormones and the endocrine system, which alter the immune system. He proposed that Growth Hormone is involved in homeostasis of the immune system during nutrient deprivation. Partitioning of nutrients away from muscle growth makes it more available for use by the immune system. Also, Growth Hormone exerts a direct positive effect on the thymus, lymphocytes and other components of the immune system.

\subsubsection{Effect of poor nutrition on recurrent infections}

The relationship between infection and malnutrition is synergistic [34]. There is evidence for both the adverse effect of infection on nutritional status and the increased susceptibility of malnourished individuals to infection. Each may worsen the other and that the potentiated effects of malnutrition and infection combined are thus greater than the sum of the two.

Specific micronutrients, for example, vitamin A, beta-carotene, folic acid, vitamin $\mathrm{B}_{12}$, vitamin $\mathrm{C}$, riboflavin, iron, zinc, and selenium have immunomodulating functions. They influence the susceptibility of a host to infectious diseases, including their course and outcome. The antioxidant properties of the micronutrients may not only regulate immune homeostasis of the host, but also alter the genome of microbes particularly viruses [35]. 


\subsubsection{Effect of poor nutrition on the endocrine system}

Early exposure to undernutrition has been strongly associated with low birth weight, epigenetic programming and functional alteration of the hypothalamo-pituitary-adrenal (HPA) axis throughout the lifespan [36]. Studies using animal models have shown that pituitary corticotrophs and the adrenal cortex are affected. In humans, recent evidence shows that there is indeed HPA-axis dysregulation [36].

\subsubsection{Effect of poor nutrition causing epigenetic changes}

There is now compelling evidence to show that poor nutrition causes epigenetic changes in animals and humans. In the Dutch hunger winter study, individuals who were prenatally exposed to famine in 1944-1945 and had poor early-life nutritional status showed DNA methylation changes at the IGF2 locus compared with their unexposed, same-sex siblings [37]. Maternal diet consistently demonstrates alteration in the offspring's epigenome [38]. These findings support previous epidemiologic studies which suggested that adult disease risk is associated with early-life environmental conditions and is greatly influenced by changing pattern of the epigenome and gene expression. The association was specific for periconceptional exposure, reinforcing that very early mammalian development is a crucial period for establishing and maintaining epigenetic marks.

\subsection{Recurrent infections}

\subsubsection{Effect of recurrent infections on nutrition}

Infections have been found to aggravate micronutrient deficiencies by reducing nutrition intake, increasing nutritional losses and interfering with utilisation via alteration of metabolic pathways [35]. Infection is a common precipitating and aggravating factor of malnutrition, while malnutrition also tends to be a major factor in the occurrence of infection [39]. This is reflected in the reciprocal interactions in Fig. 1.

\subsubsection{Effect of recurrent infections on the immune system}

Prenatal infection may further reduce the capacity of the innate neonatal immune system to respond to endotoxin; neonatal rat pups responded to challenge with significantly reduced corticosterone while maternal infection suppresses the offspring's inflammatory response to lipopolysaccharide [40].

\subsubsection{Effect of recurrent infections on the endocrine system}

In a guinea pig model, offspring of dams exposed to endotoxin during pregnancy exhibited an attenuated cortisol response to environment stress in the weaning period. In adulthood, the female offsprings had diminished cortisol response to immune challenges while both male and female offsprings exhibited altered febrile response [41].

\subsubsection{Effect of recurrent infections causing epigenetic changes}

Recurrent infections can lead to epigenetic modification of an imprinted gene, such as IGF2. Bacteria translocate to the placenta of intrauterine growth-restricted mice foetuses, and cause structural alteration within the challenged placental layer, DNA hypermethylation and down regulation of IGF2 [42]. In addition, there is increased DNA methylation at several $\mathrm{CpG}$ islands in the gastric mucosae of individuals infected with $H$. pylori compared to uninfected individuals. 


\subsection{Endocrine system}

4.5.1 Effect of the endocrine system on the immune system and epigenetics

A number of hormones, for example, growth hormones (GH), prolactin (PRL), Insulin-like Growth Factor-1 (IGF-1), glucocorticoids (GC) and thyroid hormones, have receptors in and exert biologic actions on tissues of the immune system [33]. PRL secretion in response to stress has an immunomodulatory role: it stimulates the immune system directly and reduces the degree to which GCs are secreted in response to stress. GH, PRL and IGFs all play an integral role in growth, maintenance, repair and function of the immune system [33]. These further interactions are also included in Fig. 1. Moreover, the effects of endocrine disruptors are heritable or transgenerational $[44,45]$.

\section{CONCLUSION AND FUTURE WORK}

Environmental stress is a significant health problem globally. Environmental factors such as heavy metals, malnutrition and infection affect developing countries disproportionately more. These facts emphasise the value of studying the dentition as a complex adaptive system and this Romano-British population as a well-documented, accessible source of material.

This paper builds upon previous work exploring of the dentition as a self-adaptive complex system. It demonstrated that the dentition is a valuable model for investigating the control of general development and the causes of developmental abnormalities and systemic illnesses. Many of the same genes, epigenetic and environmental influences and similar mechanisms are present during development of the dentition and of other body tissues and systems. A promising area of future research is exploring the possibility of reversing the long-term adverse outcomes of the epigenetic change.

\section{ACKNOWLEDGEMENTS}

This investigation was supported by the Australian Dental Research Foundation. We are grateful to Theya Molleson of the Natural History Museum, London, who provided not only access to material but also valuable advice and support. Contributions to the database used were made by a series of postgraduate students: L.K. Foo, C.A. Johns, M. Scheers, J.M. Smith and C.A. Underhill.

\section{REFERENCES}

[1] Honavar, V., Complex Adaptive Systems Group Iowa State University, available at http://www. cs.iastate.edu/ honavar/alife.isu.html

[2] Brook, A.H. \& O’Donnell, M.B., The dentition: a complex system demonstrating self-principles. Self-Adaptive and Self-Organizing Systems (SASO), Fifth IEEE International Conference, pp. 208-209, 2011.

http://dx.doi.org/10.1109/saso.2011.41

[3] Brook, A.H., O’Donnell, M.B., Hone, A., Hart, E., Hughes, T.E., Smith, R.N. \& Townsend, G.C., General and craniofacial development are complex adaptive processes influenced by diversity. Australian Dental Journal, 59(s1), pp. 13-22, 2014.

http://dx.doi.org/10.1111/adj.12158

[4] Bei, M., Molecular genetics of tooth development. Current Opinion in Genetics \& Development, 19(5), pp. 504-510, 2009.

http://dx.doi.org/10.1016/j.gde.2009.09.002

[5] Brook, A.H., Koh, K.S.B. \& Toh, V.K.L., Influences in a biologically complex adaptive system: environmental stress affects dental development in a group of Romano-Britons. International Journal of Design \& Nature and Ecodynamics, 11(1), pp. 33-40, 2016.

http://dx.doi.org/10.2495/DNE-V11-N1-33-40 
[6] Kaidonis, J.A., Ranjitkar, S., Lekkas, D., Brook, A.H. \& Townsend, G.C., Functional dental occlusion: an anthropological perspective and implications for practice. Australian Dental Journal, 59(s1), pp. 162-173, 2014. http://dx.doi.org/10.1111/adj.12133

[7] Painter, R.C., Roseboom, T.J. \& Bleker, O.P., Prenatal exposure to the Dutch famine and disease in later life: an overview. Reproductive Toxicology, 20(3), pp. 345-352, 2005. http://dx.doi.org/10.1016/j.reprotox.2005.04.005

[8] Painter, R.C., Osmond, C., Gluckman, P., Hanson, M., Phillips, D.I.W. \& Roseboom, T.J., Transgenerational effects of prenatal exposure to the Dutch famine on neonatal adiposity and health in later life. An International Journal of Obstetrics \& Gynaecology, 115(10), pp. 1243-1249, 2008.

http://dx.doi.org/10.1111/j.1471-0528.2008.01822.x

[9] Jirtle, R.L. \& Tyson, F.L. (eds), Enviromental Epigenomics in Health and Disease, SpringerVerlag: Berlin Heidelberg, 2013.

[10] Boekelheide, K., Blumberg, B., Chapin, R.E., Cote, I., Graziano, J.H., Janesick, A., Lane, R., Lillycrop, K., Myatt, L., Thayer, K.A. \& Waalkes, M.P., Predicting later-life outcomes of early-life exposures. Environmental Health Perspectives, 120(10), pp. 1353-1361, 2012. http://dx.doi.org/10.1289/ehp.1204934

[11] Farwell, D.E. \& Molleson, T., Poundbury Vol 2-The Cemeteries, Friary Press: Dorchester, UK, 1993.

[12] Waldron, H.A., Mackie, A. \& Townshend, A., The lead content of some Romano-British bones. Archaeometry, 18(2), pp. 221-227, 1976. http://dx.doi.org/10.1111/j.1475-4754.1976.tb00165.x

[13] Whittaker, D.K. \& Stack, M.V., The lead, cadmium and zinc content of some Romano-British teeth. Archaeometry, 26(1), pp. 37-42, 1984.

http://dx.doi.org/10.1111/j.1475-4754.1984.tb00315.x

[14] Lewis, M.E., Life and death in a civitas capital: metabolic disease and trauma in the children from late Roman Dorchester, Dorset. American Journal of Physical Anthropology, 142(3), pp. 405-416, 2010. http://dx.doi.org/10.1002/ajpa.21239

[15] Walker, P.L., Bathurst, R.R., Richman, R., Gjerdrum, T. \& Andrushko, V.A., The causes of porotic hyperostosis and cribra orbitalia: a reappraisal of the iron-deficiency-anemia hypothesis. American Journal of Physical Anthropology, 139(2), pp. 109-125, 2009. http://dx.doi.org/10.1002/ajpa.21031

[16] Brook, A.H. \& Smith, J.M., The aetiology of developmental defects of enamel: a prevalence and family study in East London, UK. Connective Tissue Research, 39(1-3), pp. 151-156, 1998. http://dx.doi.org/10.3109/03008209809023921

[17] Brook, A.H., Variables and criteria in prevalence studies of dental anomalies of number, form and size. Community Dentistry and Oral Epidemiology, 3(6), pp. 288-293, 1975. http://dx.doi.org/10.1111/j.1600-0528.1975.tb00326.x

[18] Moorrees, C.F., Thomsen, S.O., Jensen, E. \& Yen, P.K.J., Mesiodistal crown diameters of deciduous and permanent teeth. Journal of Dental Research, 36(1), pp. 39-47, 1957. http://dx.doi.org/10.1177/00220345570360011501

[19] Healey, N., Lead toxicity, vulnerable subpopulations and emergency preparedness. Radiation Protection Dosimetry, 134(3-4), pp. 143-151, 2009.

http://dx.doi.org/10.1093/rpd/ncp068 
[20] Lee, D.H., Jacobs Jr, D.R. \& Porta, M., Hypothesis: a unifying mechanism for nutrition and chemicals as lifelong modulators of DNA hypomethylation. Environmental Health Perspectives, 117, pp. 1799-1802, 2009. http://dx.doi.org/10.1289/ehp.0900741

[21] Zhao, Z., Li, R., Sun, L., Li, Z. \& Yang, R., Effect of lead exposure on the immune function of lymphocytes and erythrocytes in preschool children. Journal of Zhejiang University Science, 5(8), pp. 1001-1004, 2004. http://dx.doi.org/10.1631/jzus.2004.1001

[22] Mishra, K.P., Singh, V.K., Rani, R., Yadav, V.S., Chandran, V., Srivastava, S.P. \& Seth, P.K., Effect of lead exposure on the immune response of some occupationally exposed individuals. Toxicology, 188(2), pp. 251-259, 2003. http://dx.doi.org/10.1016/S0300-483X(03)00091-X

[23] Li, S., Zhengyan, Z., Rong, L. \& Hanyun, C., Decrease of CD4+ T-lymphocytes in children exposed to environmental lead. Biological Trace Element Research, 105(1-3), pp. 19-25, 2005. http://dx.doi.org/10.1385/BTER:105:1-3:019

[24] Selye, H., Tuchweber, B. \& Bertok, L., Effect of lead acetate on the susceptibility of rats to bacterial endotoxins. Journal of Bacteriology, 91(2), pp. 884-890, 1966.

[25] Lee, J.E., Naqi, S.A., Kao, E. \& Dietert, R.R., 2002. Embryonic exposure to lead: comparison of immune and cellular responses in unchallenged and virally stressed chickens. Archives of Toxicology, 75(11-12), pp. 717-724, 2002. http://dx.doi.org/10.1007/s00204-001-0283-9

[26] Dietert, R.R. \& Piepenbrink, M.S., Lead and immune function. Critical Reviews in Toxicology, 36(4), pp. 359-385, 2006. http://dx.doi.org/10.1080/10408440500534297

[27] Hirsch, H.V., Possidente, D. \& Possidente, B., Pb 2+: an endocrine disruptor in Drosophila? Physiology \& Behavior, 99(2), pp. 254-259, 2010. http://dx.doi.org/10.1016/j.physbeh.2009.09.014

[28] Faulk, C., Liu, K., Barks, A., Goodrich, J.M. \& Dolinoy, D.C., Longitudinal epigenetic drift in mice perinatally exposed to lead. Epigenetics, 9(7), pp. 934-941, 2014. http://dx.doi.org/10.4161/epi.29024

[29] Chen, S., Golemboski, K.A., Piepenbrink, M. \& Dietert, R.R., Developmental immunotoxicity of lead in the rat: influence of maternal diet. Journal of Toxicology and Environmental Health, Part A, 67(6), pp. 495-511, 2004. http://dx.doi.org/10.1080/15287390490276520

[30] Mahaffey, K.R., Nutrition and lead: strategies for public health. Environmental Health Perspectives, 103(Suppl 6), pp. 191, 1995. http://dx.doi.org/10.1289/ehp.95103s6191

[31] World Health Organisation (WHO), Childhood lead poisoning, available at http://www.who. int/ceh/publications/childhoodpoisoning/en/index.html

[32] Moore, S.E., Collinson, A.C., N'Gom, P.T., Aspinall, R. \& Prentice, A.M., Early immunological development and mortality from infectious disease in later life. Proceedings of the Nutrition Society, 65(3), pp. 311-318, 2006. http://dx.doi.org/10.1079/PNS2006503

[33] Davis, S.L., Environmental modulation of the immune system via the endocrine system. Domestic Animal Endocrinology, 15(5), pp. 283-289, 1998. http://dx.doi.org/10.1016/S0739-7240(98)00034-4 
[34] Scrimshaw, N.S., Taylor, C.E. \& Gordon, J.E., Interaction of Nutrition and Infection. WHO Monograph Series 57. World Health Organization: Geneva, 1968.

[35] Bhaskaram, P., Micronutrient malnutrition, infection, and immunity: an overview. Nutrition Reviews, 60(suppl 5), pp. S40-S45, 2002.

[36] Lesage, J., Sebaai, N., Leonhardt, M., Dutriez-Casteloot, I., Breton, C., Deloof, S. \& Vieau, D., Perinatal maternal undernutrition programs the offspring hypothalamo-pituitary-adrenal (HPA) axis. Stress, 9(4), pp. 183-198, 2006.

http://dx.doi.org/10.1080/10253890601056192

[37] Heijmans, B.T., Tobi, E.W., Stein, A.D., Putter, H., Blauw, G.J., Susser, E.S., Slagboom, P.E. \& Lumey, L.H., Persistent epigenetic differences associated with prenatal exposure to famine in humans. Proceedings of the National Academy of Sciences, 105(44), pp. 17046-17049, 2008. http://dx.doi.org/10.1073/pnas.0806560105

[38] Lillycrop, K.A. \& Burdge, G.C., Maternal diet as a modifier of offspring epigenetics. Journal of Developmental Origins of Health and Disease, 6(02), pp. 88-95, 2015.

http://dx.doi.org/10.1017/S2040174415000124

[39] Scrimshaw, N.S. \& SanGiovanni, J.P., Synergism of nutrition, infection, and immunity: an overview. The American Journal of Clinical Nutrition, 66(2), pp. 464S-477S, 1997.

[40] Lasala, N. \& Zhou, H., Effects of maternal exposure to LPS on the inflammatory response in the offspring. Journal of Neuroimmunology, 189(1), pp. 95-101, 2007.

http://dx.doi.org/10.1016/j.jneuroim.2007.07.010

[41] Hodyl, N.A., Walker, F.R., Krivanek, K.M., Clifton, V. \& Hodgson, D.M., Modelling prenatal bacterial infection: functional consequences of altered hypothalamic pituitary adrenal axis development. Behavioural Brain Research, 178(1), pp. 108-114, 2007.

http://dx.doi.org/10.1016/j.bbr.2006.12.008

[42] Bobetsis, Y.A., Barros, S.P., Lin, D.M., Weidman, J.R., Dolinoy, D.C., Jirtle, R.L., Boggess, K.A., Beck, J.D. \& Offenbacher, S., Bacterial infection promotes DNA hypermethylation. Journal of Dental Research, 86(2), pp. 169-174, 2007. http://dx.doi.org/10.1177/154405910708600212

[43] Maekita, T., Nakazawa, K., Mihara, M., Nakajima, T., Yanaoka, K., Iguchi, M., Arii, K., Kaneda, A., Tsukamoto, T., Tatematsu, M. \& Tamura, G., High levels of aberrant DNA methylation in Helicobacter pylori-infected gastric mucosae and its possible association with gastric cancer risk. Clinical Cancer Research, 12(3), pp. 989-995, 2006.

http://dx.doi.org/10.1158/1078-0432.CCR-05-2096

[44] Anway, M.D., Leathers, C. \& Skinner, M.K., Endocrine disruptor vinclozolin induced epigenetic transgenerational adult-onset disease. Endocrinology, 147(12), pp. 5515-5523, 2006. http://dx.doi.org/10.1210/en.2006-0640

[45] Jedeon, K., Marciano, C., Loiodice, S., Lavier, M.C.C., Berdal, A. \& Babajko, S., Enamel defects due to exposure to combinations of endocrine disruptors (abstract). IADR/ PER congress conference paper, 2014. available at https://iadr.confex.com/iadr/per14/webprogram/ Paper192149.html 